\title{
I AM NOT THE HIVE MIND OF TRANSETTI PRIME
}

\section{A difficult decision.}

\section{BY STEVEN FISCHER}

$\mathrm{I}$ am not a young girl staring up at the stars, grasping her father's hand and holding it tight.

She looks at his face, exhausted but smiling, then back again at the blanket of ink stretched above. She loves the stars on this side of the station, even though she rarely gets to see them. Even though a day off means Father will have to work extra shifts for the next week and a half.

But today that doesn't matter, because he's with her looking at the stars. At Sirius and Ursa Major, and even the pale white glimmer of Sol. She grins because these are their stars, here beneath the hum of the station's engines, purring like the tabby cat that stalks their crowded hab onboard.

As the station spins, the stars swirl slowly, tracing eon-worn ruts across the dark sky. She knows them all, or at least all with names, just as her father and his father before him.

Today she smiles, though, because she has found a new star, flickering dimly over the metal swell of the station's massive grav drive. She's waited three cycles to tell Father, because she wanted to be certain, rehearsing the named stars over and over in her mind. But this one is not named, nor does it belong to the myriad lists of those marked by just numbers.

It's a new star. Their star. Just like all the others.

Her smile widens as their star splits into two.

I am not the technician daydreaming in his chair when the cluster of red appears on the long-range sensors.

The alarms wake him quickly, not loud, but persistent. A steady, slow beep growing in volume, at first in rhythm with, then falling far behind, the beating of his heart.

It's probably a drill or a glitch in the system. Maybe debris from a wreck or a derelict vessel. He queries the endless transit databases, but there are no registered ships in that sector, and the pattern on the screen is too regular and moving too fast.

More than one sig-

DNATURE.COM Follow Futures:

y @NatureFutures

f go.nature.com/mtoodm

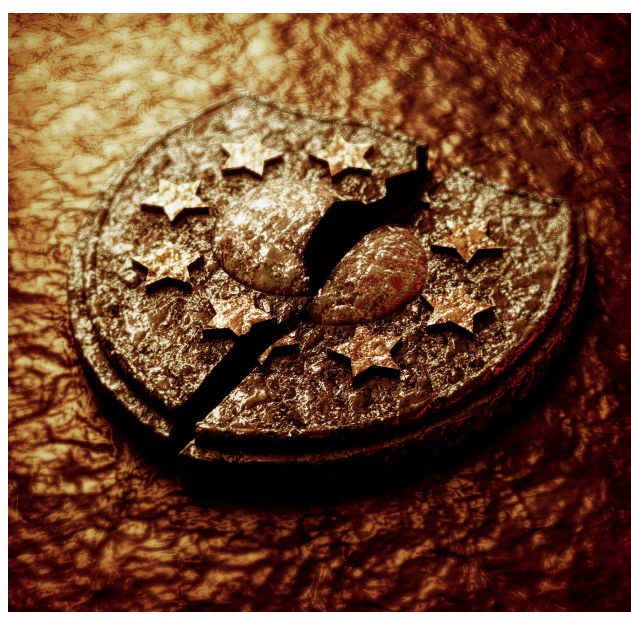

There are few things in space that move that quickly. Even fewer that would trigger the system from this distance.

He sighs, and his hand goes to his neck, fingers threading across the port beneath his skull base and the smaller, blue gem set in his skin just below. His eyes close as he thinks of the matching stone in the skin of his lover half a system away. He whispers a silent prayer of thanks that their transport isn't returning today, then he forces the system to run the numbers again.

There is no glitch, but he knew that already.

I am not the admiral roaming the bridge, inspecting data displays and bulkhead stations nestled deep within the station's metal heart.

She turns her head at the sound of hurried footsteps, a young ensign racing across the gangplank, carrying a terminal in his hands.

"Easy, soldier," she whispers, taking the display from him, a star chart with a cloud of crimson dots hovering above.

Her eyes harden into a stone-heavy grey as they sweep across the tangles of projected trajectories, and she feels the station's core come alive around her.

There are protocols for these things, put in place by intelligences far greater than hers, and the station has already made up its mind. Somewhere in the tangles of steel that surround her, thousands of missiles are dropping into place, preparing to fire the moment the station determines it has no other options.

But she doesn't need the computational power of 2 million human minds to confirm that for her. There are no other options, and their course has already been set.

She stares at the ensign and the emblem on his chest - a ring of stars inside a shield of iron - and thinks of another young officer aboard another station, bearing not just her same emblem, but her same name as well. Because the shield that guards that ring of stars is not composed just of metal and missiles, but of breath, and blood, and soldiers with sons and mothers of their own.

I am not the hive mind of Transetti Prime. Two million voices compiled into one perfect thought. Four million eyes blending into one omniscient vision.

I may have been that only seconds ago, when I triggered alarms and opened my hangars, and set every ship in its berth loose with all they could carry.

I may have been that when I locked all my doors, keeping those inside safe from each other, at least, as I could not keep them safe from what waited outside.

I may have been that when I dropped a thousand warheads into silos, preparing to return the salvo headed my way, if in the end I could do nothing to stop it.

But I am not that anymore.

I am a grizzled veteran standing at her post, unable to escape the horrors of war, but afraid only because she knows her child will face them, too.

I am a sensor technician sitting in a chair, sending a final message to his lover away for work, grateful that only one of them will die today.

I am a child, standing on the bow of a station, arms wrapped around a father who's crying for reasons she can't understand, awestruck by their good fortune and the cloud of beautiful stars streaking down around them.

I am two million lives that are already dead, and the millions more that will die if I follow my directives.

I close the ports along my bow and rest my missiles still and silent in their tubes as the first of the warheads detonate against my hull, light like starfire consuming all around me.

Steven Fischer is a resident physician in the Pacific Northwest of the United States. You can read more of his work at www. stevenbfischer.com or follow him on Twitter @stevenfischersf. 